per la resistenza ad aminoglicosidi e blaoxazo che conferisce la resistenza a beta-lattamici. La comparazione dei risultati di RAPD-PCR e analisi degli integroni ha evidenziato la presenza di un unico genotipo (Aci1) tra gli isolati da pazienti ricoverati presso la RIA del Policlinico Umberto I, tutti positivi per lo stesso integrone da $2200 \mathrm{bp}$, suggerendo la diffusione di un unico ceppo. Isolati con caratteristiche genetiche simili sono stati anche riscontrati nei ceppi dell'Ospedale M.G.Vannini e degli altri reparti del Policlinico Umberto I. Ulteriori analisi di genotipizzazione più sensibili della RAPD-PCR saranno pertanto necessarie per rilevare la presenza di ceppi clonali e per monitorarne la diffusione.

\title{
ANALISI MOLECOLARE MEDIANTE RAPD-PCR E CARATTERIZZAZIONE DEGLI INTEGRONI IN ISOLATI UMANI DI ACINETOBACTER BAUMANNII
}

Giordano A', Varesi P. ', Bertini A², Venditti M³, Carfagna P.4, Mancini C.', Carattoli A. ${ }^{2}$.

'Dip. Scienze e Sanità Pubblica Sez. Microbiologia

Università La Sapienza, Roma.

${ }^{2}$ Dip. Malattie Infettive Parassitarie ed Immunomediate,

Istituto Superiore di Sanità, Roma.

${ }^{3}$ Dip.Medicina Clinica Università La Sapienza, Roma.

${ }^{4}$ Ospedale Madre G.Vannini Medicina Interna, Roma.

Acinetobacter baumannii è un germe ubiquitario che si ritrova nel $25 \%$ della popolazione umana a livello della flora cutanea; resistente ad antibiotici è un batterio emergente come causa di infezioni nosocomiali.

In questa specie, sono state descritte resistenze ad ogni classe d'antibiotici, compresi aminoglicosidi, cefalosporine di nuova generazione e carbapenemici. In questo studio sono stati valutati 73 ceppi di $A$. baumannii isolati da maggio 2004 ad aprile 2005 da pazienti ricoverati presso la RIA ed altri reparti del Policlinico Umberto I e dalla RIA dell'Ospedale Vannini di Roma.

Tutti i ceppi sono stati identificati biochimicamente mediante card ID-GN Vitek2 (BioMérieux) e analizzati per la resistenza agli antibiotici mediante agar diffusione secondo Kirby Bauer.

I ceppi sono stati tipizzati mediante analisi RAPD-PCR che ha evidenziato la presenza di tre profili genomici (Aci1, Aci2 e Aci3).

Un'ulteriore tipizzazione dei ceppi è stata ottenuta mediante l'analisi degli integroni di classe 1: due tipi di integroni sono stati evidenziati con regioni variabili di 2200 paia di basi (bp) e $2400 \mathrm{bp}$, rispettivamente.

La regione variabile da $2200 \mathrm{bp}$, dell'integrone riscontrato in 55 ceppi tutti con profilo Acil, è stata sequenziata dimostrando la presenza della cassetta genica $a a c A 4$, che codifica 